\title{
Domesticando o Humano para uma Antropologia Moral da Proteção Animal
}

\author{
Bernardo Lewgoy \\ Universidade Federal do Rio Grande do Sul (UFRGS), RS, Brasil \\ E-mail: blewgoy@portoweb.com.br

\section{Caetano Sordi} \\ Universidade Federal do Rio Grande do Sul (UFRGS), RS, Brasil \\ E-mail: caetano.sordi@gmail.com

\section{Leandra Pinto} \\ Universidade Federal do Rio Grande do Sul (UFRGS), RS, Brasil \\ E-mail: leandraop@gmail.com
}




\section{Resumo}

Este artigo examina o campo da proteção animal em Porto Alegre (RS) a partir de um ponto de vista antropológico e etnográfico. Parte-se da hipótese de que as iniciativas contemporâneas de resgate, adoção e proteção de animais de companhia em situação de risco e de abandono - realizadas por organizações não governamentais ou por voluntários individuais - revelam a emergência de novas sensibilidades e moralidades para com os animais não humanos em contextos "pós-domésticos" (Bulliet 2005), reconfigurando as fronteiras entre o público e o privado, a esfera da intimidade e das políticas públicas. Por fim, conclui-se que o exercício de domesticação contido nessas iniciativas é uma via de mão dupla: por um lado, tenta-se disciplinar e higienizar o espaço público e a conduta dos acolhedores de animais; por outro, busca-se educar os seres humanos para o convívio com membros não humanos das famílias, tornando-os responsáveis (em sentido moral, psicológico e legal) pelas suas novas famílias multiespecíficas.

Palavras-chave: Antropologia. Moralidades. Proteção Animal. Domesticação.

\section{Abstract}

This article examines the field of animal protection in Porto Alegre (Rio Grande do Sul, Brazil) from an anthropological and ethnographical point of view. We understand that the contemporary iniciatives of rescuing, adopting and protecting endangered companion animals - carried by non-governmental organisations and multiple networks of volunteers - unfold the emergency of new sensibilities and moralities concerning urban animals in so-called "post-domestic" contexts (Bulliet, 2005), reshaping the boundaries between the private and the public well as between the spheres of intimacy and public policy. We conclude that the domestication acts implied in these initiatives are twofold: on one hand, the volunteers want to discipline and higienize the public space and the behavior of animal adopters; on the other hand, they aim to educate human beings for living toghether with non-human family members, making them responsible (in the moral, psychological and legal senses) for their new multispecific families.

Keywords: Anthropology. Morality. Animal Protection. Domestication. 


\section{Introdução}

chamada "questão animal" eclodiu como problema cultural e
lagenda de ativismo e de pesquisa em décadas recentes ${ }^{1}$. São visíveis, nos mundos público e acadêmico, inúmeras mudanças de atitudes, valores e normas que desentranham, se eticizam e que se revestem de um valor inaudito um objeto sem outro registro anterior que não o dos saberes informais de adestradores e criadores, do universo íntimo e familista dos pets ou do olhar naturalista ou industrial de biólogos, veterinários e zootécnicos. Os sinais de mudança se evidenciam nos registros públicos, acadêmico-intelectual e na vida cotidiana dos habitantes das nações modernas, com a explosão midiática e sensível de um estilo de vida que ressignifica e confere uma intensa visibilidade ao "sofrimento" e à "qualidade" de vida dos animais, domésticos ( sejam aqueles ligados ao trabalho e à alimentação, sejam os animais de estimação) ou silvestres, agora alvos de um novo olhar e compaixão. No Brasil, recentemente, governos municipais têm se empenhado na renovação de suas políticas para a gestão dos animais domésticos no meio urbano, revisando as clássicas políticas de extermínio de animais errantes, substituindo-as por abordagens de esterilização e "acolhimento responsável", mediadas por equipes multidisciplinares. Guarulhos (SP) destaca-se neste aspecto e, em Porto Alegre (RS), tem funcionado há alguns anos a Secretaria Especial dos Direitos Animais, que também tem desenvolvido ações de proteção a animais urbanos de rua.

Diversos autores têm estudado o sentido sociocultural dessas modificações das relações sensíveis, simbólicas e morais entre humanos e animais. Jean-Pierre Digard (1999), Nathalie Blanc (2003) 
e Richard Bulliet (2005), entre outros, salientam a emergência de novas configurações simbólicas oriundas, seja de uma critica erudita e pós-humanista ao dualismo natureza/cultura, homem /animal, seja de transformações populares nas sensibilidades para com os animais, especialmente as atitudes ampliadas de empatia e sentimentos de família nos quais os animais estão incluídos. Isso conduz a Antropologia à tarefa de estudar o lugar dos animais na esfera íntima, no ciclo de vida dos humanos, assim como, inversamente, dos humanos no ciclo de vida dos animais, em que a atribuição de personalidade aos animais de estimação ou silvestres passa por uma ampliação do domínio de sua agência e persona. Essa pessoalização dos animais pode ser percebida em sua "filhotização" (Ingold, 2000), mais acentuada na exacerbação da maternagem, na extrema sensibilidade para com suas necessidades e cuidados, na ampliação de especialidades veterinárias e "humanização" de seus cuidados, chegando-se ao ponto de se criarem instituições para lidar com a morte dos animais. Esse eixo é mais claro nos espaços sociais públicos e privados onde criadores, donos, veterinários e esteticistas convivem em coletivos de humanos e não humanos (Latour, 2004), definindo novas competências e práticas, especialmente em pet shops, mas também dando lugar a novos conflitos, nas ruas e nos espaços domésticos.

Os reflexos e os signos dessas mudanças disseminam-se nos diferentes registros e sistemas simbólicos da cultura, num âmbito metafórico, metonímico e literal, na arte, na literatura, na mídia e no universo cotidiano, associadas a novas cosmovisões, novos estilo de vida (veganismo, espaços de sociabilidades humano/animais, exposições de animais da pecuária, feiras e concursos de animais) em que se amplia enormemente a importância dos veterinários - novos "médicos de família", autênticos pediatras e pedagogos, mediadores da relação humanos e animais, e também o despontar de uma vigorosa economia, mercantil e moral, e de um universo de práticas e de significações ligadas ao mercado e à proteção dos animais urbanos. Essas considerações todas estão relacionadas à reconfiguração de valores e representações sobre "domesticação"/ "evolução", ao chamado "contrato doméstico" agora posto em discussão (Digard, 1999; Larrére, 2010). 


\section{Os Animais e a Organização do Meio Urbano: Estado, classificações e compaixão}

O caso das protetoras e adotantes de animais é exemplar para entender como sentimentos e expressões morais de simpatia e compaixão são levados em consideração nas trocas intra e interespecíficas relacionadas à organização do meio urbano: de um lado, os animais "indesejáveis" no convívio urbano, como insetos, algumas espécies de aves e ratos; de outro, os "animais de rua", "abandonados", recobertos pelas intervenção compassiva dos seres humanos.

Nesse âmbito há todo um dispositivo biopolítico classificatório, técnico e informal que separa os animais "selvagens" versus "domésticos", "domésticos de produção" versus "domésticos de companhia", "selvagens rurais" ("fauna de conservação" ou "vida selvagem") versus "selvagens urbanos" sujeitos a controle de zoonoses (ratos, pombos, insetos, etc.) e fauna de conservação em áreas de reserva no interior do meio urbano (exemplo: bugios, répteis e aves na reserva biológica do Campus do Vale da UFRGS, em Porto Alegre).

Toda a fauna, urbana e rural, doméstica e selvagem, é, em teoria, sujeita a dispositivos de controle biológico e regulamentos sanitários, mas o poder público costumeiramente tem seu interesse maior na fauna selvagem (Bursztyn; Bursztyn, 2012), nos animais de produção e no controle de zoonoses. Os animais domésticos de companhia estão entre os menos protegidos pelas ações governamentais, na medida em que o crescimento dos movimentos de defesa dos animais foi acompanhado de uma irresponsabilização das atribuições do poder público.

Em Porto Alegre, o cuidado de animais domésticos de companhia não é mais atribuição do controle de zoonoses desde 2005, tendo o mesmo passado à Secretaria de Proteção dos Direitos dos Animais (SEDA). No entanto, esse órgão tem praticado apenas políticas sanitárias preventivas em animais de populações de periferia (castração, vacinação e vermifugação), não se responsabilizando diretamente por abandonos ou maus-tratos a animais - atribuindo tacitamente a ONGs, protetoras individuais e abrigos filantrópicos parcialmente subsidiados pelo Estado - ambivalência que tem sobrecarregado o papel das protetoras de animais, causando-lhes grande sofrimento moral. 
Ainda no aspecto classificatório, existe uma clivagem axial - com forte ressonância moral - entre animais de companhia "adotados" (coabitação multiespecífica responsável) e "animais de rua", estes podendo ser divididos, de acordo com o sujeito classificador, em "animais abandonados" e "animais comunitários" - embora esse último epíteto seja controvertido entre protetoras que não acreditam que gatos e cachorros possam viver sem a guarda responsável de uma família humana.

Os animais de rua podem tornar-se "ferais" (espécie de animal em processo individual de "desdomesticação") quando estão, há muito tempo, distantes do convívio com seres humanos. Contudo, a adjetivação de "feral" é mais aplicada a gatos - por conterem, do ponto de vista simbólico, uma espécie de "feralidade intrínseca", mesmo entre os que são "de casa" - do que a cachorros. Estes, ao contrário, são tidos e vistos como condicionados por uma "eterna dependência" (ou "eterna infância") dos humanos.

O "animal comunitário" é típico em bairros de periferia urbana, mas essa noção é contestada por muitos protetores(as), para os(as) quais "não existe animal de rua, mas apenas animal abandonado", o que revela uma concepção bastante idealizada de configuração familiar de multiespécies calcada no modelo moral de família conjugal de camadas médias urbanas². Assim, a familiarização ou filhotização de animais de companhia os reveste de uma "função redentora" (Digard, 1999) sendo os últimos depositários de uma noção de "amor incondicional". A gramática moral da oposição entre Casa e Rua, de Roberto DaMatta (1985), acaba tendo forte incidência nessa concepção de proteção animal, especialmente se considerarmos o aspecto idealmente integrador e edênico atribuído ao universo familiar da "casa" e o caráter negativo e hobbesiano da "rua", o que Andréa Osório (2011) já tinha percebido em sua pesquisa sobre uma ONG de gatos fluminense.

Assim, no caso das protetoras de animais, as práticas, sociabilidades e concepções da fronteira humanidade/animalidade apontam para atravessamentos, passagens e para a emergência do que Latour (2004, p. 120) descreve como "novas modalidades de coletivos entre humanos e não-humanos". Os diferentes modos de proteção e ma- 
nejo da relação entre natureza e cultura para o universo dos animais domésticos de estimação, no meio urbano, criam uma dimensão de negociação e agência multiespécies (Kirksey; Helmreich, 2010) onde as Ciências Sociais, além de ultrapassar fronteiras - incluindo a essencial barreira público e privado na vida e economia moral das pessoas envolvidas na proteção animal, pouco ou quase nada destacada seja pelos filósofos abolicionistas, como Peter Singer ou Tom Regan, seja pelos antropólogos proponentes do ontological turn - deve incorporar um universo de comunicação e convívio interespecífico. Esse também é um novo desafio da etnografia, onde o "viver com" (Haraway, 2008, p. 211$)$ e a agência dos animais não-humano impõem-se de forma marcante, definindo uma inédita importância da questão animal bem além da velha narrativa evolucionista da domesticação.

\section{Novas Moralidades nas Redes de Proteção Animal}

O universo das protetoras de animais mobiliza um conjunto de recursos materiais e semióticos que exerce crucial papel agentivo em seu trabalho: instituições, automóveis, clínicas veterinárias, sites e redes na internet, advogados, policiais, clínicas veterinárias, abrigos no meio rural, simpatizantes que fornecem informações a partir dos esquadrinhamentos vicinais do meio urbano em busca de animais perdidos ou abandonados, eventos de adoção ou coleta de fundos para ajuda do trabalho de resgate e cuidado de animais resgatados. O trabalho de proteção animal é, deste modo permeado de uma situação de multiagência ligada a redes sociotécnicas (Latour, 1994) e comunicações digitais, compondo-se em maior ou menor grau e de forma muitas vezes tensa, com agentes públicos encarregados de prestar assistência e controle biopolítico da população de animais urbanos, agora situados na posição de "híbridos" entre natureza e sociedade.

O caráter essencialmente cartesiano e objetal do animal na sociedade ocidental permite ao naturalismo concebê-lo como presa, trabalhador, objeto de conhecimento, cobaia ou máquina de produção para o consumo. Mas o pet representa uma exceção ou anomalia classificatória que cria um mal-estar conceitual a esta ontologia naturalista por conter um embrião de animismo que cria zonas de exceção moral 
antropomórficas, em plena sociedade tecnoindustrial. Os espaços de maior visibilidade da causa animal nos países latinos são a proteção da vida selvagem e a proteção da vida de animais abandonados no meio urbano; enquanto nos países anglo-saxônicos, a luta contra a vivissecção e o bem-estar de animais de produção na criação, transporte e abate, assim como os grupos de ação direta contra criadouros e biotérios ocupam um lugar de destaque em suas políticas de proteção e movimentos sociais (Munro, 2005; Digard, 1999).

O conceito de "sociedade pós-doméstica", desenvolvido por Bulliet em Hunters, Herders e Hamburguers (2005), fornece importantes pistas para compreender as características recentes da sensibilidade moral para com os animais. Bulliet elabora uma periodização evolutiva-social das relações dos humanos com os animais associando a nova sensibilidade moral para os animais a um mundo onde eles não estão mais presentes no cotidiano das sociedades urbanas. Os procedimentos de morte, de esquartejamento e de exposição de animais de produção, tão familiares ao público nas sociedades domésticas, passam a ser executados em instituições invisíveis e a maior familiaridade restringese aos animais de estimação. O público urbano é altamente sensível para com animais de estimação e fauna selvagem - mas altamente ambíguos como consumidores em relação aos animais de produção - na medida em que a era pós-doméstica faz um resgate paradoxal do pré-doméstico, em que era alto o grau de subjetivação de animais não humanos, mesmo as presas de caça (similar ao "animismo" em Descola e Ingold). Essa subjetivação é, para o autor, agora resgatada e dirigida aos animais domésticos e à fauna selvagem (que em muitos lugares passa a ter uma relação diversa, "amansada" e acostumada aos seres humanos, como é o caso de lobos, guaxinins, raposas e várias espécies de macacos).

Embora seja bastante notório o complexo fenômeno de pessoas que, individual e coletivamente, ajudam animais por meio de acolhimento, alimentação, denúncia ou outras formas de ativismo, é surpreendente o pouco interesse que as Ciências Sociais têm demonstrado sobre esse objeto. Duas notórias exceções são a dissertação de Mattos (2012) sobre ajuda animalitária e o trabalho de Andrea Osório (2011) sobre "gateiras". 
Luc Boltanski (2004), em sua análise do "sofrimento a distância" (2004), desenvolve uma reflexão sobre as "políticas da piedade" de grande interesse para a compreensão do universo moral da proteção animal. Na trilha de Hannah Arendt, Bolstansky propõe uma dicotomia entre políticas de justiça, essencialmente universalistas e fundadas nas ideias de equidade e de mérito ("a cada um de acordo com seu merecimento"), e, de outro lado, as "políticas de piedade", ancoradas na emoção da simpatia, na distância (a piedade é um ato de um observador distanciado) e no valor exemplar da figura da vítima. Sendo a compaixão cristã uma ação espontânea, face a face e não necessariamente reflexiva ou política entre um benfeitor e um desafortunado, ela esgota-se em sua singularidade diádica, não sendo capaz de gerar uma cadeia causal socializante de mobilização e solidariedade. Já a piedade moderna, do contrário, tem uma dimensão política que dissocia o elo imediato e direto entre a vítima e o simpatizante e torna exemplar tanto o sofrimento da vítima - engrandecida pelo espetáculo do sofrimento - quanto a dimensão afetiva do movimento social de simpatia nele inspirado. É possível ver que a compaixão das protetoras de animais pode ser simultânea ou disjuntivamente uma compaixão cristã clássica, voltada para a ação direta pessoal e outra, moderna,

Incorporando a crítica feminista ao caráter androcêntrico e antiemotivo dos teóricos dos direitos dos animais, como Peter Singer e Tom Regan (Adams, 2010), José Parry (2011) resgata a "ética do cuidado", que propõe um papel político positivo para as emoções na formulação dos pleitos na luta pela proteção animal. Aliás, a analogia entre dominação masculina e patricarcado com relação a humanos/animais tem sido sublinhada por Donna Haraway (2008) e Carol Adams (2010), chamando a atenção para a importância do cruzamento entre questão animal e o tema do gênero.

O problema do gênero salta aos olhos no que se refere à composição majoritariamente feminina dos grupos de protetores, mas é dos mais complexos no âmbito analítico, pois é preciso escapar do senso comum naturalizador, como aponta Demello (2012), Herzog (2007) e Robertson, Gallivan e Macintyre (2004). A dedicação aos animais é muitas vezes lida na ótica do estigma de gênero (como na expressão "proteloucas") gerando esteriotipia e incompreensão, de um lado, e 
problemas concretos de grande complexidade, de outro especialmente, na vida econômica, familiar e afetiva das protetoras. De qualquer forma é possível afirmar que a proteção animal é extremamente "genderificada". Há casos de problemas intrafamiliares e separações conjugais, assim como de acordos envolvendo complexas negociações em que a questão da coabitação assim como as dívidas econômicas relacionadas aos animais é fonte permanente de tensões e conflitos na esfera íntima.

De outra parte, a associação e continuidades entre esfera íntima e esfera pública gera um modo de vida em que uma "ética do cuidado" (enfatizada, por exemplo, pelo ecofeminismo) e compaixão para com os animais vulneráveis não se dissocia de uma política de piedade para com as vítimas animais da crueldade, do abandono e dos maus-tratos humanos. As protetoras de animais muitas vezes cruzam ações de compaixão concretas, como resgatar animais da rua e acolhê-los em suas casas com um engajamento em ações e políticas de piedade e/ ou de justiça que visam sensibilizar o público - sobretudo via internet e eventos em feiras e praças - para a "adoção responsável" de cães e gatos, articulam-se em ONGs e redes sociais para a promoção de direitos dos animais na via legislativa e, por último, mas não menos importante, eles exercem contínua pressão sobre o poder executivo para o cumprimento de leis e tomada de ações para a proteção animal. Cada uma dessas ações altruístas interespecíficas - resumidas no que um dos mais veteranos estudiosos das relações humano-animais, o antropólogo Jean-Pierre Digard (1999) chama de "movimento animalitário", por analogia com "humanitário" - implica em sacrifícios pessoais, empenhos e despesas específicas, cruzando dimensões emocionais, políticas, econômicas e afetivas, afetando todas as instâncias da vida e da trajetória dos(as) informantes que serão pesquisados(as). O esforço e os sacrifícios pessoais despendidos pelos protetores(as), com sua contínua dependência do auxílio alheio para o sustento de animais resgatados relaciona-se à ideia de "economia moral" (Fassin, 2004), em que o valor da solidariedade e do altruísmo são preponderantes na gestão de trocas e fluxos econômicos, como acontece nas coletas via internet, assim como nos bazares e eventos para o patrocínio das ONGs animalitárias ou mesmo no crédito privilegiado que recebem de veterinários, pet shops e abrigos simpáticos à causa animal. 
A economia que vai do resgate à adoção exige tanto uma ordem negociada da intimidade familiar, no sentido de Zelizer (2011), quanto outra economia, semiótica e material, que, do resgate à adoção, mobiliza uma rede sociotécnica de grande complexidade, da qual participam carros, veterinários, pet shops, abrigos, remédios, computadores, divulgadores, fotografias, apoio governamental, apadrinhamentos, rituais de nominação, de esquadrinhamento e de avaliação dos adotantes (que envolvem questões de classe e confiabilidade suposta), "termos de posse responsável" assim como medidas pós-adoção, de modo a garantir a adequação e segurança do pet no novo lar.

As próprias protetoras têm se esforçado para a institucionalização de seu trabalho, criando longos questionários e contratos de adoção que vêm aproximando cada vez mais a adoção de animais à adoção de crianças humanas. O trabalho dos protetores se estende a visitas após a adoção para verificar, de tempos em tempos, a situação, a "segurança" e o "bem-estar" do animal adotado em seu novo lar³. Assim, a adoção de animais abandonados vai-se tornando uma política pública não estatal implementada por protetores(as) que segue as linhas gerais e a inspiração das políticas de proteção à infância humana.

A denúncia da crueldade/desumanidade no trato com cães e gatos abandonados, veiculada frequente e eficazmente nas redes sociais, associa-se a um pedido de piedade e direitos, evidenciado pela vulnerabilidade exposta no espetáculo das imagens de corpos de animais maltratados pela ação humana. Essa exposição é o prelúdio de uma demanda moral, acoplada a pleitos por direitos dos vulneráveis e penalização/criminalização das condutas dos responsáveis pelo sofrimento animal.

É preciso ressaltar que é pouco frequente que o interesse das protetoras a serem pesquisadas ultrapasse os animais de companhia - cães e gatos - não sendo frequente a união por mobilizações em torno de animais de trabalho ou de produção, como bois, cavalos e outras espécies. No entanto, a ação concentrada em gatos (gateiras) ou cães (cachorreiras) não indica necessariamente identidades restritivas, mas especializações por preferências individuais, embora já se tenha constatado que, em suas casas, é comum que as protetoras tenham cães e gatos mantidos e criados juntos como animais de estimação. 
O pleito por direito de certos animais em situação de vulnerabilidade nem sempre se confunde com um ativismo pelos direitos dos animais. Essa é uma das fontes de tensão entre as protetoras e os grupos abolicionistas (Sordi, 2011), o que gera um campo de discursos repleto de atritos, divergências e acusações mútuas, mas também de negociação de consensos mínimos e articulações táticas, quando se trata de diálogos com o poder público ou com os representantes do poder legislativo.

Não se trataria tanto de um problema de espécies privilegiadas (de onde provém a acusação de "especismo"), mas de uma proximidade física e existencial e do testemunho direto do sofrimento de determinados animais em um ambiente pós-doméstico urbano, enquanto os chamados animais de produção (porcos, bois, cabras, galinhas, etc.) pertencem a um distante mundo doméstico e rural, isso sem falar na fauna selvagem cujo contato, mesmo que altamente simpático, dá-se via televisão e internet.

Por último, mas não menos importante, há uma dimensão de classe social nas concepções, práticas e tensões internas entre protetores(as) e entre estes e os potenciais adotantes de animais. Liziane Mattos (2012) observou preconceitos de classe e raça atuando em alguns casos de discriminação do adotante, encaminhando a análise para um maior aprofundamento dessas dimensões de classe, raça, gênero, política, da família e da economia. Observações preliminares com informantes indicam o surgimento eventual de tensões e ressentimentos de classe, seja com grupos de maior capacidade diferencial de mobilização de contatos, recursos materiais e relações com profissionais e políticos (por vezes ironizadas como "as madames da proteção animal") seja, na direção oposta com grupos de com menos recursos mobilizáveis para a aquisição de doações de vulto para seus "brechós", eventualmente estigmatizadas como "pobres" pelas primeiras. Há inclusive, divisão de espaços da cidade de acordo com o perfil dos grupos participantes, num gradiente que vai das classes médias para as de maior poder aquisitivo, clivagens que influenciam as estratégias e modos singulares de organizar o altruísmo interespecífico de acordo com o grupo em questão. 


\section{O Cotidiano da Proteção Animal: ativismo, accountability e política de reputações}

Neste mais de doze anos de resgates e denúncias, já presenciei muitas coisa terríveis. Me deparei com muitas pessoas realmente más, que judiavam de animais indefesos, como se não fossem vidas. Ao mesmo tempo, conheci centenas de pessoas com o coração gigante, que abdicam do próprio conforto para salvar animais, que dedicam suas vidas e fazem de tudo para salvar os peludos. Porém, muitas pessoas de coração gigante, acabam se perdendo dentro da sua própria vontade de ajudar os peludos, e acabam, sem perceber, prejudicando a si e aos animais! São os chamados acumuladores de animais. Sem dúvida é uma doença, e é muito difícil fazer com que a pessoas enxergue a realidade. (Mell, 2014)

Das muitas pessoas que simpatizam com o sofrimento de animais, existem aquelas que os resgatam da rua. Quando essa prática se torna central na subjetivação e modo de vida do indivíduo, sua identidade passa a ser considerada de protetor(a) de animais. Essa identidade pode ter tanta centralidade que todas as demais dimensões de sua existência social podem ficar subordinadas ao imperativo moral do altruísmo interespecífico. Esta entrada na proteção animal insere a pessoa, em sua grande maioria de classes médias urbanas, numa rede solidária de protetoras e ativistas com preocupações, valores e práticas em comum. Mas essa situação cria, de outro lado frequentes tensões com outros significativos, especialmente familiares e vizinhos, que podem chegar a estigmatizar moralmente a(s) pessoa(s) em questão ("protelouca $\left.(s)^{\prime \prime}\right)^{4}$. De outra parte é comum que os lares temporários tornem-se definitivos para os animais.

O resgate do animal individual é feito diretamente pela protetora quando a mesma o localiza na rua, mas há protetoras que fazem rondas após o seu trabalho em territórios ou zonas delimitados da cidade, muitas vezes próximos de sua moradia ou no caminho de casa após o trabalho ${ }^{5}$. As situações descritas variam de acordo com a espécie (cão ou gato) e o temperamento do animal ("mais dócil", "mais arisco", "mais agressivo", "menos agressivo", etc.). Os cães são os mais fáceis de resgatar, por isso as protetoras sempre portam um pouco de ração e 
uma coleira. No caso dos gatos, a parceira com profissionais especializados em resgate (os taxidogs) é fundamental sendo necessário o uso de armadilhas (as "gatoreiras") e um tempo maior para atrair os animais. Os cachorros podem ir provisoriamente para a casa da protetora ou da resgatante, e os gatos vão imediatamente para a clínica veterinária de apoio a fim de passar por uma avaliação médica.

O resgate é descrito como "o momento de maior satisfação no trabalho da proteção". Mas a entrevistada ressalvou que é preciso cuidar para evitar o erro da adição ao resgate, que, por vezes, pode levar uma pessoa a se tornar acumuladora de animais. ${ }^{6}$

A dificuldade no resgate de cães e gatos é inversamente proporcional à facilidade de sua adoção: gatos são facilmente adotáveis, independente de raça, sexo ou pelagem, enquanto cães vira-latas podem ficar anos numa casa de passagem, ao contrário dos cães de raça, muito disputados para adoção (a despeito das inúmeras campanhas para a desconstrução da fronteira conceitual entre cães de raça e vira-latas).

Explica-se o que fazer com o animal, para que clínica de baixo custo confiável levar, como tratar dele, sendo gato ou sendo cachorro (casos diversos), etc. Ademais, orienta-se como, passada a fase inicial de medicalização e abrigamento inicial (avaliação médica, tratamento, vermifugução e castração), encaminhar o animal para adoção.

No caso de nossa interlocutora-chave, estudante da UFRGS e membro de pequena ONG de proteção de animais, o desemparo de seu primeiro resgate (2011) logo foi convertido em êxito, graças ao apoio de uma ampla rede de protetoras veteranas, atuante no Facebook, que lhe proveu de toda a informação e apoio necessários não apenas para lidar com os animais resgatados como para a formação de uma ONG de proteção animal ${ }^{7}$. Esse tipo de solidariedade é fundamental para a reprodução de saberes e valores que definem uma normatividade nos costumes atuais da proteção animal, gerando uma intensa sociabilidade e circulação de informações entre protetores, simpatizantes (que podem atuar com protetores eventuais), doadores (que doam materiais ou dinheiros para as protetoras), padrinhos (que ajudam com doações regulares a animais de casas de passagem) ou e parceiros (clínicas veterinárias, transportes especializados ou taxi-dogs, 
passeadores, donos de casas de passagens, veterinários, fotógrafos, web designers, etc.).

A entrevistada referiu-se à mudança no modelo de proteção animal em relação às antigas sociedades protetoras de animais, que abrigavam quaisquer animais (algumas ainda o fazem) encaminhados por particulares. Hoje em dia, o novo modelo é o de consultoria para pessoas fazem contato, pois há muitos casos de falsos resgates, pessoas que querem descartar animais alegando tê-los encontrado ou de mero descompromisso com o testemunho do abuso ou abandono ${ }^{8}$.

Ao novo protetor de animais é apresentado um mundo de conexões e moralidades intraespecíficas, fundado na confiança mútua e na constante vigilância (esta com vários sentidos) como valores, o que significa, entre outras coisas, a existência de listas de maus protetores e listas de adotantes não confiáveis, uma espécie de "SPC" informal da proteção animal. Essa questão é muito complexa, pois não há institucionalização, certificação externa ou avaliação pública da qualidade dos integrantes da rede sociotécnica: não há senão relações de confiança através dos prestígios e reputações formados na carreira moral de protetores, adotantes e parceiros. Sendo inteiramente dependente dessa política de reputações, a preocupação em isolar más protetoras, maus adotantes e maus parceiros é constante nas redes de proteção animal.

Como nas histórias que os balineses contam para si mesmos sobre si mesmos, de Geertz, um grande número de narrativas - as chamadas fofocas - termo êmico - sobre má conduta circula informalmente entre as protetoras sobre outras protetoras. Os exemplos mais típicos são os das protetoras que não prestam contas, protetoras que pegam os chamados casos extremos (doenças raras ou de difícil tratamento) para receber mais dinheiro, protetoras que castram os animais para clínicas proibidas (de má-reputação por não apresentarem condições adequadas e receberem um grande número de animais para aumentar sua receita), protetoras que maltratam animais e protetoras (e abrigos) que não doam animais sob sua guarda para continuar a receber dinheiro de padrinhos.

No entanto, nossa interlocutora-chave adverte que um grande número de acusações de "comportamento desviante" origina-se da rivalidade pessoal e subjetiva entre protetoras e que, muitas vezes, 
é difícil a tarefa de separar a informação que procede da mera maledicência, o filtrar a fofoca. Como em "Família, Fofoca e Honra", de Cláudia Fonseca (2000), a fofoca parece estar imbuída de uma forte qualidade relacional de proximidade e distância (a má-conduta é quase sempre atribuída à pessoa com quem não tenho laços de amizade e proximidade, o que inversamente, me faz relativizar o erro de quem me é próximo) misturada a outras considerações, mais objetivas, no julgamento do comportamento alheio. Tudo se passa como se as fofocas contivessem uma composição heteróclita de exageros, má-fé e informações reais, sendo uma espécie de mal necessário.

É difícil, mas torna-se imprescindível a tarefa de não se deixar levar e filtrar a fofoca. Não se pode abrir mão dessa fonte potencial de informação, sugerindo uma autêntica "educação da atenção" - no sentido de Ingold (2000) - um discernimento conquistado ao longo do tempo. O resultado é a formação de listas de indivíduos desviantes, protetores, adotantes e parceiros que funcionam quase como "caixas-pretas" no sentido de Latour (1988): algo que, uma vez estabelecido arregimenta força, aliados e alianças, gozando de credibilidade, estabilidade no tempo e resistindo aos testes de força.

A verificação de um "nome sujo" de má-protetora numa lista impede a divulgação de seus pedidos nas redes sociais, assim como ocorre com os maus adotantes, que tem listas próprias. A diferença está na privacidade relativa das informações: enquanto a lista de maus adotantes é uma caixa-preta sólida, consensual e facilmente compartilhada entre todas as protetoras, as listas de más protetoras e maus parceiros são mais instabilizáveis, mais discretas e menos compartilhadas abertamente, quase não se encaixando na definição laturiana de caixa-preta, pelas razões supramencionadas, de maior potencial de subjetividade e relacionalidade na qualidade da informação (o que é reconhecido pelas próprias). Portanto, no mundo proteção animal, solidariedade, reputação e tensão interpessoal são como gêmeas inseparáveis, formando a "caixa-preta" do nome da protetora, ONG, instituição ou parceiro espécie de honra pessoal ou capital simbólicomoral diferencialmente acumulado ao longo do tempo.

Do ponto de vista moral é também central o problema da accountability na economia moral da proteção animal. Em suma é central 
na proteção como carreira moral virtuosa, uma política de reputações. Não havendo uma auditoria fiscal externa ou certificação oficial das ONGs e protetoras individuais, as mesmas estão condicionadas a uma política de reputações, que envolve atividades como documentar em detalhes, com notas e imagens (rações, tratamentos veterinários, remédios, evolução do estado de saúde dos animais, abrigados ou adotados, etc.) o uso das doações recolhidas. Nesse sentido, há um grande comprometimento e esforço pessoal em estar constantemente oferecendo provas do bom uso dos recursos. Sendo a accountability uma tarefa central, é frequente que uma pessoa da ONG assuma a tarefa, enquanto outras se dedicam ao resgate, e outras ao contato e divulgação das adoções, consultorias, etc.

As chamadas protetoras profissionais são altamente estigmatizadas por duas razões interligadas: em primeiro lugar porque não prestam contas de forma considerada adequada (ou simplesmente não prestam contas). A desorganização e as possíveis "boas intenções" não amenizam a reprovação moral dessa conduta (com suposição de auferir lucros pessoais), na medida em que se supõe que ela coloca em risco toda a economia moral da proteção, a qual é baseada inteiramente na transparência da prestação de contas.

Além de prestações de contas defeituosas ou inexistentes, da ausência de documentação por imagens das compras e despesas realizadas, há suspeitas de má conduta quando uma protetora exibe várias contas bancárias individuais para doação e, em casos mais extremos, descobre-se que frauda imagens de cachorros em más condições de saúde para apelar a doadores. Outras situações características envolvem importantes parceiros das resgatantes, como clínicas veterinárias de castração a baixo custo (que, para efeitos de obtenção de lucros, podem funcionar em condições inadequadas por falta de higiene e equipamentos apropriados), casas de passagem fraudulentas ou mesmo, tutoras temporárias que se apegam demasiado aos animais ao ponto de não admitir a adoção. O desvio de doações ocorre quando uma gestora de lar temporário ou tutora temporária recusa a visita de inspeção aos animais resgatados, não exibe imagens deles ou, em casos mais extremos, chega a negar a adoção de animais sob sua guarda (para continuar a receber doações). Muitas vezes, eles são 
descobertos em péssimas condições de saúde, sem abrigo, higiene ou sem alimentação (alimentados com rações de baixa qualidade, vencidas, ou alimentos humanos de baixa qualidade). Essa situação é fonte de diversas tensões, incluindo ameaças à integridade física de protetoras, que podem ter de recorrer à autoridade policial para apoiar o novo resgate de animais abrigados.

O debate entre vocacão e profissão subjaz a alguns dos dilemas da proteção animal. Para várias protetoras ainda predomina a ideia de proteção como vocação altruísta e feminina a ser separada da remuneração pecuniária, tida como "poluída" ou "fonte de corrupção" da proteção séria.

Para uma de nossas interlocutoras, isso seria um eco da visão de que as mulheres tem uma vocação natural para profissões ligadas ao cuidado, como enfermeiras, psicólogas, professoras de creche, ensino primário, babás, cuidadoras de idosos e acompanhantes de doentes. Mas há uns poucos e atuantes homens na proteção animal que desfazem a essencialização desta associação, carregada de esteriotipia. O paradoxo é que essa mesma esteriotipia gera uma desconfiança, a respeito dos homens que buscam adoção de animais, por desconfiarse da inaptidão dos homens aos cuidados necessários com os bichos. O caso típico de maior apreensão é o do homem adulto solteiro que entra em contato em busca de cadela não castrada, pelo temor de tratar-se de um zoófilo em busca de uma parceira canina.

Assim, se a espécie humana é hobbesianamente estigmatizada como fonte do mal radical e do abuso e crueldade contra os animais, há uma implícita essencialização do gênero masculino como "representante natural" dessa tendência à crueldade e uma cobrança moral maior das mulheres para desempenharem o papel "natural" de mães de animais de estimação (muitas vezes chamados de "bebês" ou pela sigla "BB" muito comum nas redes sociais). Por isso, quando há reversão de expectativas em relação a adotantes do sexo feminino, a indignação moral das protetoras pode atingir um nível máximo, justamente pela essencialização reversa da aptidão suposta do feminino para os "cuidados maternos".

Além de doações, as protetoras contam com parceiros, clínicas veterinárias, taxidogs e casas de passagem que lhes fornecem descontos 
especiais e pagamento fiado. Essa economia moral da proteção animal completa-se com doações de roupas, objetos usados e livros para a realização de brechós, jantares e outros eventos beneficentes (como o Brechocão em Porto Alegre), quando as ONGs arrecadam dinheiro para amenizar o constante endividamento a que estão sujeitas pelo incessante trabalho de proteção e resgate de animais de rua. Na verdade esse circuito de economia moral é fundamental para o trabalho de proteção: a mesma não se viabilizaria sem o crédito e os descontos dos parceiros e estes não seriam pagos sem a importante fonte de receitas representada pelas doações e brechós.

\section{Adoção de Animais como Ordem Negociada: domesticando os humanos para a família multiespécies}

A seguir, o animal no "lar provisório" é antropomorfizado em imagens e textos para ficar apto a ser divulgado em álbuns de animais para adoção. Nessas imagens o animal deve estar em excelente aparência, pois, segundo nossa interlocutora-chave, "[...] adotantes não se interessam por animais com aspecto de maltratados, deprimidos ou doentes". Devem estar de banho tomado e com adereços (gravatas, chapéus e bandanas coloridas para os machos, florzinhas e colares de pérolas para as fêmeas), num ambiente que pode contar com lençóis limpos, doces e cupcakes $^{9}$. Essas imagens são acompanhadas de um texto em que se descreve o perfil do animal. Nas palavras de nossa interlocutora, este é o momento em que se monta a personalidade do animal para adoção.

Passada a fase do resgate, da medicalização, do abrigamento, da montagem da personalidade do animal, este passa a figurar nos diversos álbuns que divulgam os animais para adoção. Os interessados fazem contatos e inicia-se uma nova fase, não isenta de novos dilemas e dramas morais. O interessado recebe um questionário onde se avalia se o perfil do animal é adequado à família do adotante, suas rotinas e características. Por exemplo, há casos de incompatibilidade do animal com a família interessada, que acarretam a devolução do mesmo, sendo este um grande motivo de preocupação das protetoras ${ }^{\mathbf{1 0}}$. 
Importa salientar que o questionário é lido por todos os membros da ONG da entrevistada para efeito de consenso. Se há mais de um candidato a adotante assume-se que pode haver critérios subjetivos envolvidos na escolha do adotante. Salienta-se que se trata de longo questionário, em que as respostas devem ser detalhadamente respondidas e o próprio tempo da devolução do questionário ajuda a formar uma impressão sobre o(s) adotante(s). Muitas situações de hábitos, mudanças, conflitos com vizinhança, doenças, alimentação e dificuldades de temperamento são perguntadas no questionário a fim de familiarizar o candidato a adotante com as complexidades da guarda de um pet. Mas a exigência da casa telada para gatos (por se achar desnecessária ou cara) e a queixa sobre a intrusão na privacidade da vida familiar previsto no contrato de adoção, são as reclamações mais comuns dos candidatos que desistem da adoção. Do lado das protetoras há exclusões em casos em que se desconfia da negligência, abandono ou possibilidade de maus-tratos dos animais nas respostas do questionário.

Os gatos pretos inspiram cuidados maiores para as protetoras (pelo preconceito social ainda operante em relação a eles e pela suposição da possibilidade de seu sacrifício em rituais de magia negra, especialmente em datas como o Halloween e Sexta-feira 13). Ainda no caso de adotantes de gatos e cães há certas reservas, por parte de algumas protetoras, em relação a perfis de jovens que pareça rebeldes ou desajustados (por suposição de violência e negligência em potencial) e participantes de religiões afro-brasileiras (pela reprovação do sacrifício de animais e pelo receio de que gatos possam ser ali sacrificados em cerimônias religiosos) $)^{11}$. Muitos contatos, reais e virtuais podem ser feitos nessa fase, a fim de conhecer melhor o candidato a adotante. Presume que o conjunto de instrumentos e interações permitirão avaliar se o candidato tem condições de assumir a guarda do animal.

Além disso, o controle sobre o animal adotado é frequentemente visto como uma invasão de privacidade, assim como são considerados exagerados o questionário e o termo de adoção por muitos adotantes, sob a alegação de uma memória familiar anterior totalmente diversa com os animais de casa. Muitas desistências de adoções ocorrem na 
fase de contatos, ouvindo-se não raro, queixas de um absurdo excesso de burocracia para a adoção de animais que tanto precisam de um lar.

$\mathrm{O}$ passo seguinte é verificar se o candidato não consta em alguma lista. Passada esta etapa, o animal a ser adotado será entregue diretamente na casa do adotante, que deverá assinar um contrato de adoção com o adotante. Neste contrato, o direito de visita do protetor e o fornecimento constante de informações solicitadas são tópicos cruciais sem os quais, o adotante assume, ao assinar, que pode perder a guarda do animal.

Do ponto de vista emocional e moral essa etapa é potencialmente a mais dramática na proteção, pois, a despeito de todas as precauções dos contatos, este é o momento em que reina a incerteza sobre o destino e a segurança do animal a ser adotado. Há casos de recusa à adoção durante a visita à casa, por informações falsas prestadas ou por verificação de detalhes adicionais, como o tipo de tratamento dispensado aos animais já residentes naquele lar ${ }^{\mathbf{1 2}}$.

Além do filtro de listas de maus adotantes, há questões ligadas à possibilidade do vinculo provisório do abrigante/resgatante flertar com a permanência pela facilidade de apego ao animal, o mesmo motivo que pode borrar a fronteira entre os protocolos de precaução com o adotante e o zelo excessivo. "Nem sempre uma frieza inicial indica que o adotante não será amoroso e zeloso com o animal" - advertiu-nos uma de nossas interlocutoras.

A seguir, tendo sido encaminhado para a nova casa, o cão ou gato adotado recebe visitas periódicas da protetora encarregada, para obter informações sobre os cuidados e a adaptação ao novo lar do animal. Esse período pode dar lugar a conflitos quando são descobertas negligências, uso de gatos para a caça de ratos, alimentação com rações consideradas inadequadas, animal isolado com correntes, sem espaço, usado como cão de guarda, não cumprimento da promessa de castração de filhotes, fuga de animais da casa e doações não previstas do animal para terceiros (que são condenadas pelas protetoras, preferindo-se a devolução do animal às mesmas, quando se trata de inadaptação.). O sintoma é detectado quando o adotante pára de fazer contatos ou de responder aos telefonemas e contatos virtuais com pedidos de in- 
formação sobre os animais adotados. O resgate de animais sob a nova guarda, não apenas em situação de vulnerabilidade e risco - animais de rua, animais sofrendo maus tratos em residências, obras ou canis - mas também frutos de adoções mal-sucedidas é fonte de tensões posteriores em que não raro repetem-se situações conflituosas descritas em algumas casas de passagem.

Como uma tarefa de Sísifo a proteção animal desdobra-se numa opção humanitária individual, existencial e/ou coletiva interminável de fazer frente a renúncias e tensões, de repetir os mesmos gestos, de confrontar as mesmas derrotas e congratular-se com as mesmas (pequenas) vitórias, alimentando-se de um manancial de apoio intelectual e moral de outras pessoas envolvidas na mesma tarefa. Um universo urbano de mulheres de camadas médias, em que tensão e solidariedade, dádiva e antagonismo são os propulsores morais deste ativismo intra e interespecífico.

\section{Conclusão: infância humana e vida de pet}

Alguns dos principais móveis de conflitos entre protetoras e adotantes podem ser vistos sob uma nova luz quando se toma os conceitos de "doméstico" e de "pós-doméstico" como categorias analítico-descritivas num sentido ideal-típico e heurístico, e não descrição estanque de etapas evolutivas, como quer Richard Bulliet. Vários dos motivos de indignação das protetoras com "candidatos" ou "maus adotantes" advêm das divergências entre os valores atribuídos no registro pósdoméstico ao animal de estimação como pet e membro filhotizado da família multiespécies - ou seja, orbitando na constelação ideal da "infância" - e as antigas e entranhadas relações tradicionais com animais domésticos, usados como animais de trabalho, como o uso de gatos para caçar ratos ou de cachorros como cães de guarda, além de uma compreensão menos vigilante, ou mesmo desleixada, sobre a movimentação, higiene, aparência, saúde, exercício e alimentação e a saúde do animal ${ }^{13}$.

Além do boom do mercado de produtos e serviços pet - com a intensa medicalização de cães e gatos, atraindo toda a indústria da biomedicina, refletindo-se na reprodução das especialidades huma- 
nas no mundo veterinário, com a consequente elevação de custos de equipamentos e de tratamento especializado, de rações premium, etc. - uma grande subjetivação, personalização e moralização - sintetizado no termo "petshismo", Digard (1999) - pelas redes de proteção animal desponta como um dos traços mais marcantes do novo registro pósdoméstico da relação com animais de estimação. Tudo se passa como se emergisse uma nova modalidade informal de vigilância biopolítica, como uma "polícia das famílias multiespécies", para usar a expressão de Jacques Donzelot, mas uma novidade geradora de novos conflitos numa sociedade com uma longa história de relação utilitária com animais.

O clamor e os movimentos sociais por maior regulação legal e funcionamento efetivo de organismo públicos de proteção de animais que se destaca na primeira parte do texto - vem coroando essa intensa atividade pessoal e demanda moral coletiva de colocação dos animais domésticos de estimação num estatuto simbólico similar ao da infância humana. Esta, objeto de um sem-número de intervenções, regulações incessantes conflitos na esfera pública (Fonseca; Schuch, 2009), parece fornecer um roteiro para os atuais conflitos, representações, práticas e moralidades que envolvem a proteção animal.

A domesticação dos humanos, por via da proteção animal, é um trajeto de mão dupla, se excetuarmos a terceira via da institucionalização biopolítica das relações com os animais: se, de um lado, as protetoras buscam domesticar e higienizar moralmente a ação de outras protetoras, por outro lado buscam educar os seres humanos para o convívio com novos membros não humanos das famílias, tornando-os responsáveis no sentido moral, psicológico e legal pelo novo núcleo familiar.

\section{Notas}

1 As fontes etnográficas dessa parte do texto são observações participantes em diversos eventos da proteção animal (reuniões, brechós, marchas, atos públicos), o contato informal de alguns anos com diversas protetoras, o acompanhamento do trabalho de ONGs e protetoras individuais em blogs e páginas no Facebook (a maioria com a confidencialidade mantida), as diversas páginas informativas sobre proteção animal de veículos como a Agência de Notícias dos Direitos dos Animais e 
uma longa entrevista com uma interlocutora-chave (ou "informante-chave") com quem já se vinha travando um contato informal há dois anos.

2 Muitas protetoras presumem que o animal de estimação deve compartilhar a cama com seus donos, repudiando a antiga casa de cachorro ou a corrente em patios de casas como situações de "abuso"ou "crueldade" com os cães.

3 Há casos em que, tendo os protetores invocado a ajuda do Estado (polícia militar e secretaria de direitos dos animais) e alegando o descumprimento da legislação e de cláusulas do contrato de adoção, os adotantes perdem a guarda do animal.

4 Há muitas narrativas de protetoras que sofrem tensões intrafamiliares, separações conjugais e conflitos com vizinhos pela dedicação à causa animal, causando um grande sofrimento emocional e sensação de abandono. Há inclusive uma clínica de psicanálise, em Porto Alegre, que faz um trabalho de atendimento psicológico gratuito voltado para protetoras de animais.

5 Ou sob denúncia, cuja avaliação é criteriosa pelas protetoras com o fito de evitar abandonos disfarçados.

6 "A acumulação compulsiva é uma patologia psiquiátrica que tem como característica a aquisição ou coleta de alguma coisa e a incapacidade de descartá-la. A Síndrome dos Acumuladores de Animais (Animals Hoarder), ou colecionismo animal, é considerada um grave sintoma e pode indicar a presença de uma doença mental mais séria. Conclui-se, em grande parte dos casos, que é um sinal de Transtorno Obsessivo Compulsivo (TOC)". Disponível em : <http://www.agendapet.com. br/2012/12/acumuladores-de-animais-altruismo-ou-doenca-.html > . Acesso em : 15 out. 2014.

7 Para essa interlocutora, que atua desde 2011 na proteção animal com uma ONG, a internet foi o grande divisor de águas para a proteção animal, permitindo a rápida formação de comunidades e redes de troca de informação, assim como a articulação da proteção individual com o ativismo coletivo

8 A crueldade ou abuso com os animais reveste-se de várias facetas, desde os maustratos (prisao com correntes, ser trancado em casa sem água e comida) ao abandono e assassinato do mesmo. Há muitos casos de descarte de animais após o dia das crianças (por rejeição do "presente") e no início das férias de verão. Mesmo sendo delito previsto no artigo 32 da Lei Federal n. 9.605/98, é imenso o número de casos relatado por protetores em sites e nas redes sociais.

9 Há, inclusive, fotógrafos especializados em pets que colaboram com a produção de imagens para álbuns de adoção.

${ }^{10}$ O caso típico de incompatibilidade é o do filhote agressivo em casas que tem crianças pequenas.

11 Além do questionário, o exame informal do perfil no Facebook pode ser usado como instrumento adicional para conhecimento e coleta de impressões sobre o adotante, onde não se descartam preconceitos de classe na restrição da adoção, para algumas protetoras.

12 Este foi relatado o caso de uma cadela presa por um fio de nylon na casa no dia da visita por alguém que, pelo questionário, parecia ser um bom adotante. A adoção, obviamente, foi cancelada.

13 A própria castração é questionada por alguns adotantes ou candidatos, especialmente em machos caninos, pela valorização subjacente da virilidade e agressividade masculina como características desejáveis do animal. Mesmo a oferta de castrações gratuitas encontra resistência, especialmente entre guardiões masculinos de pets machos. 


\section{Referências}

ADAMS, Carol J. The Sexual Politics of Meat: a feminist-vegetarian critical theory. New York: Continuum, 2010.

BLANC, Nathalie. La place de l'animal dans les politiques urbaines.

Communications, [S.1.], v. 74, p. 159-175, 2003.

BULLIET, Richard. Hunters, Herders and Hamburgers: the past and future of human-animal relationships. New York: Columbia University Press, 2005.

BURSZTYN, Maria Augusta; BURSZTYN, Marcel. Fundamentos de política e gestão ambiental. Rio de Janeiro: Garamond, 2012

BOLTANSKI, Luc. Distant suffering: morality, media and politics. Cambridge: Cambridge University Press, 2004.

DAMATTA, Roberto. A casa \& a rua: espaço, cidadania, mulher e morte no Brasil. São Paulo: Brasiliense, 1985.

DEMELLO, Margo. Animals and society: an Introduction to HumanAnimal Studies. New York: Columboa University Press, 2012.

DIGARD, Jean-Pierre. Les Français et leurs animaux. Paris, Fayard, 1999.

FASSIN, Didier. La cause des victimes. Les Temps Modernes, [S.1.], v. 59, n. 627, p. 73-91, 2004.

FONSECA, Cláudia. Família, fofoca e honra. Porto Alegre: EDUFRGS, 2000.

FONSECA, Cláudia; SCHUCH, Patrice. (Org.). Políticas de proteção à infância: um olhar antropológico. Porto Alegre: EDUFRGS, 2009.

HARAWAY, Donna. When species meet. Minneapolis: University of Minnesota Press, 2008.

HERZOG, Harold A. Gender differences in human-animal interactions: a review. Anthrozoös, [S.1.], v. 20, n. 1, p. 7-21, 2007.

INGOLD, Tim. The Perception of the environment: essays on livelihood, dwelling and skill. Londres: Routledge, 2000.

KIRKSEY, S. Eben; HELMREICH, Stefan. The emergency of multispecies ethnography. Cultural Anthropology, [S.l.], v. 4, n. 5, p. 546-576, 2010.

LATOUR, Bruno. Jamais fomos modernos: ensaio de antropologia simétrica. São Paulo: 34, 1994.

Ciência em ação: como seguir cientistas e engenheiros sociedade afora. São Paulo: UNESP, 1988. 
Políticas da natureza: como fazer ciência na democracia. Bauru: EDUSC, 2004.

LARRÉRE, Raphaël. Le loup, l'agneau et l'éleveur. Ruralia, [S.l.], n. 5, p. 2-11, 1999.

MATTA, Roberto da. A casa e a rua: espaço, cidadania, mulher e morte no Brasil. Rio de Janeiro: Rocco, 1997.

MATOS, Liziane. Quando a ajuda é animalitária: um estudo antropológico sobre sensibilidades e moralidades envolvidas no cuidado e proteção de animais abandonados a partir de Porto Alegre-RS. 2012. 190 p. Dissertação (Mestrado) - Universidade Federal do Rio Grande do Sul, Porto Alegre, 2012.

MELL, Luísa. Blog da protetora e comunicadora Luísa Mell. [2014]. Disponível em: <http://luisamell.com.br/o-limite-entre-proteger-osanimais-e-virar-um-acumulador-conheca-triste-historia-da-rosana-eacompanhe-mais-um-resgate-emocionante-emergencia-animal>. Acesso em: 16 out. 2014.

MUNRO, Lyle. Confronting Cruelty: moral orthodoxy and the challenge of Animal Rights Movement. Boston: Brill, 2005.

OSÓRIO, Andrea. Humanidade e não-humanidade: notas sobre um grupo de protetores de gatos de rua. In: $4^{\circ}$ SEMINÁRIO DE PESQUISA DO INSTITUTO DE CIÊNCIAS DA SOCIEDADE E DESENVOLVIMENTO REGIONAL. Universidade Federal Fluminense - UFF. Campos dos Goytacazes, RJ, Brasil, em março de 2011. Anais... Campos dos Goytacazes, RJ, Brasil, 2011.

PARRY, José. Sentimentality and the Enemies of Animal Protection. Anthrozoös, [S.l.], v. 24, n. 2, p. 117-133, 2011.

PASTORI, Érica. Perto e longe do coração selvagem: um estudo antropológico sobre animais de estimação em Porto Alegre/RS. 2012. 200 p. Dissertação (Mestrado) - Universidade Federal do Rio Grande do Sul, Porto Alegre, 2012.

ROBERTSON, Jessie C.; GALLIVAN, Joanne; MACINTYRE, Peter D. Sex differences in the antecedents of animal use attitudes. Anthrozoös, [S.l.], v. 17, n. 4, p. 306-319, 2004.

SORDI, Caetano. O animal como próximo: por uma Antropologia dos movimentos de defesa dos direitos animais. Cadernos IHU Ideias, São Leopoldo: Unisinos, ano 9, v. 147, 2011.

ZELIZER, Viviana. A negociação da intimidade. Petrópolis: Vozes, 2011.

Recebido em 29/05/2015

Aceito em 25/11/2015 